\title{
Vorwort zur Gesamtausgabe
}

Die Gesamtausgabe der Werke von Karl Marx und Friedrich Engels (MEGA) wird auf der Grundlage vereinbarter Beschlüsse des Zentralkomitees der Kommunistischen Partei der Sowjetunion und des Zentralkomitees der Sozialistischen Einheitspartei Deutschlands veröffentlicht. Sie ist eine Gemeinschaftsarbeit der Institute für Marxismus-Leninismus beim ZK der KPdSU und beim ZK der SED. Die MEGA enthält das gesamte literarische Erbe von Marx und Engels in den Originalsprachen : ihre Werke und Artikel, Entwürfe und unvollendeten Manuskripte, die von ihnen verfaßten Dokumente der Arbeiterbewegung, ihre Briefe sowie ihre Exzerpte, Konspekte, Notizbücher und Randbemerkungen in Büchern.

Eine derartige Ausgabe entspricht dringenden Bedürfnissen der Wissenschaft und der revolutionären Praxis in der gegenwärtigen Epoche, da die marxistisch-leninistische Theorie im gesellschaftlichen Leben zunehmende Bedeutung gewinnt und die historische Größe der Leistung von Marx und Engels als Begründer des wissenschaftlichen Kommunismus immer überzeugender sichtbar wird.

Karl Marx und Friedrich Engels gebührt ein hervorragender Platz in der Entwicklung des fortschrittlichen Denkens und des Kampfes um grundlegende soziale Umgestaltungen in der Welt. Sie begründeten die revolutionäre Theorie als geistige Waffe der fortschrittlichen gesellschaftlichen Kräfte, die zum Sturz der Ausbeuterordnung berufen sind. Ihre Theorie bringt umfassend die Lebensinteressen der Arbeiterklasse und aller anderen Werktätigen zum Ausdruck und übt wachsenden Einfluß auf das 
Denken und Handeln von Millionen Menschen in allen Ländern der Erde aus. Sie bereitete die wichtigste Wende in der Menschheitsgeschichte vor: die Wende von einer Gesellschaft der Ausbeutung, der sozialen und nationalen Unterdrückung, zum Sozialismus und Kommunismus, einer Ordnung, die den Menschen die Möglichkeit gibt, alle ihre Fähigkeiten und Fertigkeiten zum Wohle der Gesellschaft und jedes einzelnen voll zu entfalten.

Marx und Engels waren jedoch nicht nur große Gelehrte, sondern ebenso revolutionäre politische Kämpfer. Sie nahmen unmittelbar an der Revolution von 1848/49 teil. Sie begrüßten begeistert die erste proletarische Revolution, die Pariser Kommune von 1871, und verteidigten mutig die gerechte Sache der Pariser Proletarier. Sie leiteten unmittelbar die Tätigkeit des Bundes der Kommunisten und der I. Internationale, jener ersten politischen Organisationen der Arbeiterklasse, deren Traditionen in der internationalen kommunistischen und Arbeiterbewegung der Gegenwart lebendig sind.

Die Lehre von Marx und Engels entstand als Ergebnis der kritischen Aneignung und Weiterentwicklung der besten Leistungen der vorangegangenen Wissenschaft, der gründlichen Analyse der Okonomie und Politik des Kapitalismus, der Klassenverhältnisse und des Klassenkampfes sowie aus der Erkenntnis der Unversöhnlichkeit der Interessen von Ausgebeuteten und Ausbeutern in der bürgerlichen Gesellschaft. Diese Lehre ist nicht nur eine neue Etappe in der Geschichte der Philosophie, der politischen Ökonomie und der Theorie vom Sozialismus. Sie bedeutete eine wahrhaft revolutionäre Umwälzung im gesellschaftlichen Denken, die Verwandlung des Sozialismus aus einer Utopie in eine Wissenschaft.

Die von Marx und Engels in schöpferischer Gemeinschaft ausgearbeitete dialektisch-materialistische Philosophie, die politische Okonomie und der wissenschaftliche Kommunismus sind in ihrer Gesamtheit ein in sich geschlossenes System philosophischer, ökonomischer und sozialpolitischer Lehren und stellen die einzige wissenschaftliche Weltanschauung dar.

Auf dem Gebiet der Philosophie brachen Marx und Engels entschieden mit dem Idealismus, darunter mit dem Idealismus Hegels. Kritisch überwanden sie auch die Hegelsche Dialektik und schufen die materialistische Dialektik. "Meine dialektische Methode", schrieb Marx im Nachwort zur zweiten Auflage des ersten Bandes des „Kapitals", ,ist der Grundlage nach von der Hegelschen nicht nur verschieden, sondern ihr direktes Gegenteil. Für Hegel ist der Denkprozeß, den er sogar unter dem Namen Idee in ein selbständiges Subjekt verwandelt, der Demiurg des Wirklichen, das nur seine äußere Erscheinung bildet. Bei mir ist umgekehrt das Ideelle nichts 
andres als das im Menschenkopf umgesetzte und übersetzte Materielle." Die marxistische Dialektik ist die umfassendste und inhaltlich reichste Lehre von der Bewegung und Entwicklung, das Ergebnis der gesamten, jahrhundertealten Geschichte des Denkens, die theoretische Verallgemeinerung der gesellschaftlichen Praxis in ihrer historischen Entwicklung.

Marx und Engels stellten die Dialektik auf eine feste materialistische Grundlage und schufen damit den dialektischen Materialismus als die Wissenschaft von den allgemeinen Gesetzen der Natur, der Gesellschaft und des menschlichen Denkens. Die von ihnen ausgearbeitete Methode der materialistischen Dialektik ist auf die Erforschung aller Bereiche des materiellen und geistigen Lebens anwendbar. Die größte Entdeckung und ein unschätzbares Verdienst von Marx und Engels war die Anwendung des Materialismus und der Dialektik auf das Gebiet der gesellschaftlichen Erscheinungen, die Erarbeitung des historischen Materialismus, wodurch die Lehren von der Gesellschaft auf eine wissenschaftliche Grundlage gestellt wurden. Marx entwickelte den wissenschaftlichen Begriff der ökonomischen Gesellschaftsformation, er deckte die dialektische Einheit der materiellen Produktivkräfte der Gesellschaft und der ihnen entsprechenden Produktionsverhältnisse auf und zeigte, daß die Gesamtheit der Produktionsverhältnisse, die ökonomische Struktur der Gesellschaft, ihre reale Basis bilden und den Charakter des juristischen und politischen Überbaus sowie das gesellschaftliche Bewußtsein bestimmen. Marx und Engels betrachteten den historischen Prozeß als die gesetzmäßige Aufeinanderfolge ökonomischer Gesellschaftsformationen, die letzten Endes durch die Entwicklung der Produktion bedingt ist. Mit der materialistischen Geschichtsauffassung wiesen sie den einzig richtigen Weg zu einer fruchtbaren Erforschung der Vergangenheit, zur Analyse der gesellschaftlichen Verhältnisse und zur wissenschaftlichen Voraussicht.

Marx und Engels erforschten die Gesetzmäßigkeiten der Herausbildung und Entwicklung der kapitalistischen Produktionsweise und bewiesen die Unvermeidlichkeit der revolutionären Umgestaltung der bürgerlichen zur sozialistischen Gesellschaft. Der Eckpfeiler ihrer ökonomischen Lehre ist die Mehrwerttheorie. Marx enthüllte den Mechanismus der kapitalistischen Ausbeutung. Er wies nach, daß stets ein bestimmter Teil unbezahlter Arbeit durch den Kapitalisten angeeignet wird. Die Produktion von Mehrwert, so erkannte Marx, ist das absolute, allgemeine Gesetz der kapitalistischen Produktionsweise, das Hauptziel der Produktion im Kapitalismus.

Im Gegensatz zur gesamten vorangegangenen politischen Ökonomie untersuchte er zunächst den Mehrwert rein als solchen, um danach zur Untersuchung seiner besonderen Formen überzugehen. Marx formulierte 
erstmals das Bewegungsgesetz der kapitalistischen Produktionsweise, die ihr gesetzmäßig innewohnende, historische Tendenz, deren Resultat die "Expropriation der Expropriateure", die Schaffung des gesellschaftlichen Eigentums an den Produktionsmitteln, der Sieg des Sozialismus ist. In ihren Arbeiten begründeten Marx und Engels wesentliche Merkmale der sozialistischen Gesellschaft und schufen die Grundlagen für die politische Okonomie des Sozialismus.

Marx und Engels studierten den Ursprung und das Wesen der Klassen in der Gesellschaft sowie die soziale Struktur Englands, Frankreichs, Deutschlands, der USA und anderer Länder. Sie wiesen als erste wissenschaftlich nach, daß der Kapitalismus nicht ewig existiert, wie die bürgerlichen Ökonomen, Soziologen und Historiker annahmen, und daß die Teilung der Gesellschaft in Klassen nur an bestimmte historische Phasen der Produktion gebunden ist. Die von Marx und Engels geschaffene Theorie des Klassenkampfes ermöglichte es, in der Vielfalt der historischen Erscheinungen und Ereignisse die Gesetzmäßigkeiten der gesellschaftlichen Entwicklung zu finden. Die Schlußfolgerungen und wissenschaftlichen Prognosen von Marx und Engels über das unvermeidliche Anwachsen der inneren Widersprüche des Kapitalismus, über die Unmöglichkeit, die sozialen Gegensätze und scharfen Antagonismen auf der Grundlage des Privateigentums an den Produktionsmitteln zu beseitigen, sowie über den revolutionären Sturz der kapitalistischen Ordnung haben ihre historische Bewährungsprobe voll und ganz bestanden.

Marx und Engels bewiesen, daß der Klassenkampf in der bürgerlichen Gesellschaft mit Notwendigkeit zur Errichtung der politischen Herrschaft des Proletariats, zur Diktatur des Proletariats führt, die ihrem Wesen nach den Staat der Übergangsperiode vom Kapitalismus zum Sozialismus darstellt. Das Endziel des Proletariats ist die Errichtung der klassenlosen, der kommunistischen Gesellschaft, in der die höchste Entwicklungsstufe der gesellschaftlichen Produktivkräfte und des gesellschaftlichen Reichtums erreicht wird. Im Prozeß der sozialistischen Umgestaltung der Gesellschaft schließt das Proletariat die anderen werktätigen Klassen und Schichten als Verbündete um sich zusammen. Die Klarstellung der welthistorischen Rolle des Proletariats ist das Wichtigste am Marxismus. Marx und Engels wiesen ferner nach, daß die Arbeiterklasse ihre historische Mission nur erfüllen kann, wenn sie sich als politische Avantgarde eine revolutionäre Partei schafft, die den gesamten Prozeß der revolutionären Umgestaltung leitet. Die Notwendigkeit einer Kampfpartei der Arbeiterklasse als entscheidende Voraussetzung für den Sieg des Sozialismus und Kommunismus hoben Marx und Engels besonders an Hand der Erfahrungen und Lehren der Pariser Kommune hervor. 
Mehr als je zuvor wird in unseren Tagen sichtbar, daß die Arbeiterklasse die revolutionäre Hauptkraft des gesellschaftlichen Fortschritts ist. Die Erfahrungen der internationalen Arbeiterbewegung haben bewiesen: Je größer ihre Aufgaben im Kampf um die Verwirklichung ihrer welthistorischen Mission werden, je bestimmender ihr Einfluß auf den gesellschaftlichen Entwicklungsprozeß ist, um so wichtiger ist die Wahrung und Festigung der Einheit ihrer Reihen. Die Begründer des wissenschaftlichen Kommunismus betonten immer wieder, daß das Proletariat der Macht des internationalen Kapitals den engen Zusammenschluß seiner nationalen Abteilungen zu einer einheitlichen Armee im Weltmaßstab, die Treue zu den Prinzipien des proletarischen Internationalismus entgegenstellen muß. "Die vergangene Erfahrung", schrieb Marx in der Inauguraladresse der I. Internationale, ,hat gezeigt, wie Mißachtung des Bandes der Brüderlichkeit, welches die Arbeiter der verschiedenen Länder verbinden und sie anfeuern sollte, in allen ihren Kämpfen für Emanzipation fest beieinanderzustehen, stets gezüchtigt wird durch die gemeinschaftliche Vereitlung ihrer zusammenhangslosen Versuche."

Marx und Engels beschäftigten sich hauptsächlich mit den Gesellschaftswissenschaften, waren aber zugleich vorzügliche Kenner der Naturwissenschaften und lieferten hervorragende Beispiele für die philosophische Verallgemeinerung naturwissenschaftlicher Erkenntnisse. Von ihnen stammen geniale Prognosen über die wachsende Rolle der Wissenschaft im Leben der Gesellschaft. Unter den Bedingungen der wissenschaftlichtechnischen Revolution, die sich seit der Mitte des 20. Jahrhunderts stürmisch entfaltet, sind die Feststellungen der Begründer des Marxismus über das Verschmelzen von Wissenschaft und Produktion und über die Verwandlung der Wissenschaft in eine unmittelbare Produktivkraft besonders bemerkenswert.

Der Marxismus verkörpert die organische Verbindung von revolutionärer Wissenschaft und revolutionärer Praxis. Das bedeutet sowohl, daß die marxistische Lehre die Erfahrungen der revolutionären Bewegung verallgemeinert, als auch, daß die marxistischen Ideen durch den revolutionären Kampf der Arbeiterklasse und aller Werktätigen für den Kommunismus verwirklicht werden.

Die Werke von Marx und Engels sind nicht nur Ergebnisse ihres Wirkens als Theoretiker, sondern zugleich ein vortreffliches Zeugnis ihrer intensiven Tätigkeit als aktive Teilnehmer und Führer der Arbeiterbewegung, als kämpferische Publizisten und Organisatoren revolutionärer Aktionen der Volksmassen. Der Kampf von Marx und Engels um die Vereinigung aller Kräfte der Arbeiterklasse, um die Ausarbeitung einer revolutionären Strategie und Taktik des Proletariats und um seinen internationalen Zusam- 
menschluß, um die Durchsetzung der Prinzipien des proletarischen Internationalismus in der Arbeiterbewegung ist von bleibender Bedeutung. In den Werken von Marx und Engels spiegeln sich die Höhepunkte der revolutionären Bewegung ihrer Zeit wider; in ihnen dokumentiert sich die untrennbare Einheit von revolutionärer Theorie und revolutionärer Politik.

Die Stärke und Lebenskraft des Marxismus beruhen auf seiner Wissenschaftlichkeit und seiner revolutionären Parteilichkeit. Er entstand, entwickelte und festigte sich in entschiedenem und unversöhnlichem Kampf gegen die bürgerliche und kleinbürgerliche Ideologie, gegen Sozialreformismus und Anarchismus, gegen nationale Begrenztheit, Chauvinismus wie auch gegen nationalen Nihilismus, gegen Dogmatismus und Sektierertum, kurz: gegen alle Schattierungen des Opportunismus in der Arbeiterbewegung.

Von Anfang an übten die Ideen von Marx und Engels einen organisierenden Einfluß in der Arbeiterbewegung aus. Sie bildeten die Grundlage für das Programm und die Taktik der ersten internationalen Organisationen des Proletariats - des Bundes der Kommunisten und der Internationalen Arbeiterassoziation - sowie der sozialistischen und Arbeiterparteien mehrerer Länder. Die marxistische Theorie weist der Arbeiterklasse den Weg zur erfolgreichen Lösung ihrer strategischen und taktischen Aufgaben unter den unterschiedlichen historischen Bedingungen des Befreiungskampfes, zur revolutionären Umgestaltung der gesellschaftlichen Verhältnisse.

Ein wichtiger Wesenszug des Marxismus ist die ihm innewohnende Dynamik, die Fähigkeit zur ständigen Entwicklung und Bereicherung durch die Verallgemeinerung neuer gesellschaftlicher Prozesse und neuer Erkenntnisse der Wissenschaft. Marx und Engels wandten sich entschieden gegen jede Unterschätzung der Bedeutung der revolutionären Theorie. Gleichzeitig verurteilten sie alle Versuche, ihre Theorie auf eine Sammlung starrer Formeln und fertiger Rezepte zu reduzieren; sie lehnten jede Dogmatisierung theoretischer Schlußfolgerungen und taktischer Mittel ab. Der Marxismus wendet sich gegen Konservativismus und Stagnation im wissenschaftlichen Denken ebenso wie im gesellschaftlichen Leben.

Deshalb ist es ganz natürlich, daß auch die Theorie des Marxismus ständig durch neue Erkenntnisse bereichert wird. Marx und Engels wollten und konnten nicht alle Wechselfälle des historischen Prozesses darstellen. Sie erarbeiteten die grundlegenden wissenschaftlichen Prinzipien, die für das Verständnis der allgemeinen Richtung der gesellschaftlichen Entwicklung und ihrer Gesetzmäßigkeiten eine zuverlässige Orientierung darstellen. 
Die weitere Entwicklung der Lehre von Marx und Engels, die großen Siege des Marxismus im 20. Jahrhundert sind vor allem mit dem Namen Wladimir Iljitsch Lenins verbunden. Er begann in einer Zeit welthistorischer Umwälzungen zu wirken, einer Zeit, die durch revolutionäre Stürme und gesellschaftliche Erschütterungen gekennzeichnet war: in der Epoche des Imperialismus und der proletarischen Revolution. Der Leninismus ist die Errungenschaft und die theoretische Waffe der gesamten internationalen Arbeiterklasse. Er ist der Marxismus der Epoche des Imperialismus und der proletarischen Revolution, der Epoche der allgemeinen Krise des kapitalistischen Systems, des Zusammenbruchs des Kolonialismus und des Sieges der nationalen Befreiungsbewegung, der Epoche des Übergangs der Menschheit vom Kapitalismus zum Sozialismus und zur Errichtung der kommunistischen Gesellschaft. Die revolutionäre Theorie dieser Epoche wird daher zu Recht Marxismus-Leninismus genannt. Völlig haltlos sind die Versuche bürgerlicher und revisionistischer Ideologen, den Leninismus als nationale, spezifisch russische Erscheinung abzutun.

Als wahrer Revolutionär verteidigte Lenin die Lehre von Marx und Engels gegen die Angriffe ihrer offenen Feinde wie auch gegen die Revisionisten, jene, die diese Lehre für „veraltet” erklärten und sie verfälschten. Unter den veränderten historischen Bedingungen, als der Kapitalismus in sein imperialistisches Stadium eintrat, als die proletarische Revolution und die Errichtung des Sozialismus auf die Tagesordnung traten, entwickelte Lenin den Marxismus als Ganzes weiter und bereicherte ihn durch zahlreiche neue Entdeckungen. Lenin stützte sich auf die Lehre von Marx und Engels, er analysierte Ökonomie und Politik seiner Zeit, die neuen Erkenntnisse der Wissenschaft, den Kampf der Arbeiterklasse und der nichtproletarischen werktätigen Schichten, den Kampf der Volksmassen gegen das Monopolkapital, für Demokratie und Sozialismus. Auf dieser Basis entwickelte er alle Bestandteile der marxistischen Theorie weiter: den dialektischen und historischen Materialismus, die marxistische politische Ökonomie und den wissenschaftlichen Kommunismus. Es ist das bleibende Verdienst Lenins, daß er die wichtigsten Probleme des revolutionären Prozesses und der Schaffung der kommunistischen Gesellschaft unter den Bedingungen der Existenz und des Kampfes zweier Weltsysteme - des sozialistischen und des kapitalistischen - ausarbeitete und damit eine Antwort auf die Fragen gab, die von der gesellschaftlichen Entwicklung in der neuen Epoche aufgeworfen wurden.

Lenin vervollkommnete die wissenschaftliche Strategie und Taktik des internationalen Proletariats. Er gründete die Kommunistische Partei der Sowjetunion, deren Tätigkeit und Erfahrungen von größter internationaler Bedeutung sind, er erarbeitete die theoretischen, ideologischen und poli- 
tischen Prinzipien für den Kampf der kommunistischen Weltbewegung der Gegenwart. Lenin leitete die erste siegreiche proletarische Revolution in der Geschichte : die Große Sozialistische Oktoberrevolution 1917 in Rußland. Sie eröffnete eine neue Ära in der Menschheitsgeschichte, die Epoche des Übergangs vom Kapitalismus zum Sozialismus im Weltmaßstab. Sie war der erste weltweit sichtbare Triumph des Marxismus-Leninismus. Lenin gründete und lenkte den ersten sozialistischen Staat in der Welt und stand an der Spitze des Kampfes der Arbeiterklasse und ihrer Verbündeten für den Sieg des Sozialismus.

Die Leninsche Etappe in der Entwicklung des Marxismus findet ihre Fortsetzung in der theoretischen Tätigkeit der marxistisch-leninistischen Parteien der Arbeiterklasse. Der Marxismus-Leninismus wird in der Gegenwart weiterentwickelt vor allem in den Dokumenten der kommunistischen und Arbeiterparteien, in den Dokumenten und der revolutionären Praxis der internationalen kommunistischen Bewegung.

Die Errichtung des Sozialismus in der UdSSR, die Zerschlagung des Faschismus im zweiten Weltkrieg, der Sieg der sozialistischen Revolution in einer Reihe von Ländern, die Entstehung des sozialistischen Weltsystems, die Erfolge der Völker der sozialistischen Gemeinschaft beim Aufbau der neuen Gesellschaft, die Erfolge der Arbeiterklasse in den Ländern des Kapitals, der Zusammenbruch des Kolonialsystems des Imperialismus, der Kampf der Völker in den befreiten Ländern für die Festigung der nationalen Unabhängigkeit und für sozialen Fortschritt sowie der beispiellose Aufschwung des antiimperialistischen Kampfes all das zeugt von der Richtigkeit des Marxismus-Leninismus und beweist die Unvermeidlichkeit seines Sieges. Die Praxis bestätigt, daß nur auf der Grundlage des Marxismus-Leninismus die komplizierten Probleme richtig gelöst werden können, die die gegenwärtige Epoche aufwirft. Seit der Marxismus den historischen Schauplatz betreten hat, brachte und bringt ihm jede neue große Epoche der Weltgeschichte neue Bestätigung und neue Siege.

Der Marxismus-Leninismus ist das unerschütterliche theoretische Fundament der internationalen kommunistischen Bewegung, der Avantgarde aller revolutionären Kräfte, die das Streben nach Frieden eint. Er erhellt unter den Bedingungen des siegreichen realen Sozialismus die Entwicklungswege der Gesellschaft, bildet die theoretische und ideologische Grundlage für die Innen- und Außenpolitik der kommunistischen und Arbeiterparteien in den Staaten der sozialistischen Gemeinschaft. Er weist der Volksmacht Weg und Ziel. Unter den Bedingungen der kapitalistischen Ordnung wendet sich die Arbeiterklasse und ihre politische Vorhut dem Marxismus-Leninismus zu, um Strategie und Taktik des politischen 
Kampfes für die Nah- und Fernziele festzulegen. Ihrem Wesen nach international, wird die marxistisch-leninistische Lehre für die Arbeiterklasse in den kapitalistischen Ländern immer mehr zur theoretischen Waffe in ihrem Kampf gegen die Monopole und für die progressiven Kräfte der Entwicklungsländer zu einer Hilfe bei der Wahl der besten Formen und Methoden der nationalen und sozialen Entwicklung. Es ist deshalb gesetzmäßig, daß die marxistisch-leninistischen Parteien die Verbreitung der Ideen und Werke von Marx, Engels und Lenin, die umfassende Aneignung der revolutionären Theorie, ihre schöpferische Weiterentwicklung, ihre konsequente Verteidigung gegen alle Gegner stets als eine ihrer wichtigsten und dringlichsten Aufgaben betrachteten und betrachten.

In der Tatsache, daß der Marxismus die Prüfungen der Geschichte bestanden hat und seinen Siegeszug durch die Welt fortsetzt, liegt der Hauptgrund für das zunehmende Interesse an marxistischer Literatur, insbesondere an den Arbeiten von Marx, Engels und Lenin. Das hat zur Folge, daß die Zahl der verschiedenen Ausgaben der Werke von Karl Marx und Friedrich Engels wie auch von W.I. Lenin überall stark anwächst. Die Klassiker des Marxismus-Leninismus sind die meistgelesenen Autoren in der Welt. Allerorts steigt die Nachfrage nach ihren Werken.

Die Werke von Marx, Engels und Lenin wurden und werden in viele Sprachen der Welt übersetzt und finden Leser in den unterschiedlichsten Kreisen. Überall zeigt sich das Streben nach einem umfassenden, gründlichen Studium ihrer Arbeiten, spürt man erhöhte Aufmerksamkeit für die Publikation neu aufgefundener Handschriften und Dokumente, für neue biographische Materialien.

Zahlreiche bürgerliche Ideologen, die auf die wachsende Nachfrage nach den Werken der Klassiker des Marxismus-Leninismus spekulieren, publizieren immer häufiger Texte von Marx, Engels und Lenin und geben sie in tendenziöser Auswahl heraus oder versehen sie mit antimarxistischen Vorworten und Kommentaren. Die einen verfälschen den Marxismus, indem sie die Werke des jungen Marx den Arbeiten des reifen Marx oder die Gedanken von Marx und Engels den Ideen von Lenin gegenüberstellen. Andere konstruieren einen Gegensatz zwischen der Lehre von Marx, Engels und Lenin und der Theorie und Praxis der kommunistischen Bewegung in der Gegenwart oder propagieren die falsche These vom „Pluralismus" des Marxismus. Jedoch sind die Behauptungen vom „,Pluralismus" des Marxismus, von seinen angeblichen inneren Widersprüchen und andere Erfindungen durchaus kein originelles Manöver der „Kritiker" des Marxismus-Leninismus. Diese verschiedenartigen Versuche bürgerlicher Ideologen bezwecken nichts anderes, als den Marxismus in einen abstrakten Humanismus bürgerlich-liberaler Prägung umzufälschen und ihn damit 
seines revolutionären Kerns zu berauben: der Lehre von der historischen Mission der Arbeiterklasse, von der Diktatur des Proletariats, von der unvermeidlichen revolutionären Ablösung der kapitalistischen durch die sozialistische Produktionsweise, vom notwendigen Sieg des Kommunismus.

Seit der Zeit, da Marx und Engels lebten, wirkten und kämpften, sind Jahrzehnte vergangen. Aber die Begründer des Marxismus üben durch ihre wissenschaftliche Theorie nach wie vor unvermindert Einfluß auf das Weltgeschehen aus. Aus ihr schöpft jede neue Generation, die sich in den Kampf gegen kapitalistische Ausbeutung, gegen Imperialismus und Krieg, für eine glückliche sozialistische Zukunft der Menschheit einreiht, Unbeugsamkeit, Wissen und Siegeszuversicht. Wie ein Treueschwur auf ihre Lehre klingen auch heute die begeisterten Worte Lenins über Marx und Engels: „.... das sind wirkliche Menschen! Von ihnen muß man lernen. Diesen Boden dürfen wir nicht verlassen."

Wissenschaftler in aller Welt wenden sich immer häufiger den Originaltexten von Marx und Engels zu, begnügen sich nicht mehr mit übersetzten Ausgaben, wollen sich ausführlich mit den authentischen Texten bekannt machen, die Entwicklung der Gedanken von Marx und Engels im Detail verfolgen, die Methoden und Verfahrensweisen ihres wissenschaftlichen Schaffens sowie ihre Terminologie studieren.

Die objektiven Erfordernisse der gesellschaftlichen Entwicklung, die zunehmende Ausdehnung und Stärkung des revolutionären Weltprozesses sowie der gegenwärtige ideologische Kampf stellen dringend die Aufgabe, den literarischen Nachlaß von Marx und Engels vollständig herauszugeben, und zwar in einer Form, die es gestattet, die Geschichte der theoretischen und praktischen Tätigkeit von Marx und Engels allseitig zu studieren. Diesem Zweck dient die Marx-Engels-Gesamtausgabe.

Die Ausgabe, die sich auf alle bei der Edition von Marx-Engels-Texten gesammelten Erfahrungen stützt und die Ergebnisse der Marx-EngelsForschung auswertet, soll das gesamte literarische Erbe der Begründer des wissenschaftlichen Kommunismus der fortschrittlichen Menschheit zugänglich machen. Die Herausgeber lassen sich dabei in methodologischer Hinsicht von Lenins Ausführungen über die Entstehung, die Herausbildung und die wichtigsten Entwicklungsetappen des Marxismus leiten. Diese Prinzipien erfordern ein konkret-historisches Herangehen bei der Analyse der Ideen von Marx und Engels. Das verdient um so mehr hervorgehoben zu werden, als bürgerliche "Marxologen", die in der Regel die Bedeutung des Marxismus für die Gegenwart negieren, nicht selten gleichzeitig einige Thesen aus den frühen Schriften von Marx - als sich dessen Weltanschauung erst herausbildete - verabsolutieren und die Weiterentwicklung der marxistischen Theorie ignorieren. 
Die beiden herausgebenden Institute sehen es als eine ehrenvolle Verpflichtung an, die Gesamtausgabe der Werke von Karl Marx und Friedrich Engels nach den neuesten Erkenntnissen der Marx-Engels-Forschung und der Editionswissenschaft zu veröffentlichen. Auf diese Weise wird die Marx-Engels-Gesamtausgabe der weiteren Verbreitung marxistischer Kenntnisse in der Welt dienen.

Die Herausgabe der Arbeiten von Karl Marx und Friedrich Engels war stets organischer Bestandteil des Prozesses der Entwicklung und Verbreitung des Marxismus, seiner Bestätigung im revolutionären Befreiungskampf der internationalen Arbeiterklasse. Marx und Engels selbst maßen der Veröffentlichung ihrer Werke und deren Übersetzung in verschiedene Sprachen erstrangige Bedeutung bei. Sie unternahmen große Anstrengungen, um die notwendigen Verbindungen zu Verlagen herzustellen und versahen neue Ausgaben mit entsprechenden Vorworten. Es ist bekannt, welche Aufmerksamkeit sie der Veröffentlichung solcher Werke wie "Manifest der Kommunistischen Partei", „Das Kapital" u.a. schenkten. Der Vorbereitung der verschiedenen Ausgaben des "Kapitals" widmete Engels mehr als zehn Jahre seines Lebens.

Die revolutionären Vertreter der internationalen Arbeiterbewegung erkannten in den Arbeiten von Marx und Engels eine mächtige geistige Waffe im Klassenkampf und betrachteten ihre Veröffentlichung sowie die Aneignung und schöpferische Anwendung der marxistischen Ideen als wichtigste Voraussetzung für den Sieg der Arbeiterklasse. Mit dem Wachsen der internationalen Arbeiterbewegung, mit der Entstehung und raschen Entwicklung revolutionärer Parteien nahm auch die Anziehungskraft der Ideen von Marx und Engels unaufhaltsam zu. Ihre Schriften fanden weite Verbreitung. In diesem Prozeß wurde es zu einer immer dringenderen Notwendigkeit, das literarische Erbe der Begründer des wissenschaftlichen Kommunismus in größeren, geschlossenen Werkausgaben zu publizieren.

Erste Versuche, gesammelte Werke von Marx und Engels herauszugeben, gab es bereits zu ihren Lebzeiten. Marx selbst begann kurze Zeit nach der Revolution von 1848/49 eine zweibändige Ausgabe seiner Schriften vorzubereiten, die das Mitglied des Bundes der Kommunisten Hermann Becker in Köln herausgeben sollte. Die Arbeiten mußten jedoch nach dem Erscheinen der ersten Lieferung wegen der Verhaftung des Verlegers eingestellt werden. Nach Beendigung der Arbeit am dritten Band des „Kapitals" begann Engels mit der Vorbereitung einer Ausgabe gesammelter 
Werke von Marx und von sich selbst. Sein Tod setzte dieser Arbeit ein Ende.

Eleanor Marx-Aveling begann Ende der neunziger Jahre mit Veröffentlichungen aus dem literarischen Erbe von Marx und Engels. Sie gab einige Sammelbände mit Werken von Marx und Engels aus den fünfziger Jahren heraus.

Die Führung der deutschen Sozialdemokratie, in deren Archiv ein großer Teil des handschriftlichen Nachlasses der Begründer des Marxismus aufbewahrt wurde, ließ eine Reihe bis dahin unbekannter Manuskripte von Marx und Engels, einen Teil ihrer Briefe und einige bereits früher gedruckte publizistische Arbeiten, hauptsächlich aus der Presse der vierziger und fünfziger Jahre, in Einzelausgaben sowie in Zeitschriften, darunter in der "Neuen Zeit", veröffentlichen. Einen wichtigen Platz unter diesen Publikationen nahm die von Franz Mehring erarbeitete und 1902 erschienene Ausgabe von Werken aus den vierziger Jahren ein. Das war der erste Versuch, vergessene und praktisch unzugängliche Arbeiten von Marx und Engels aus der ersten Zeit ihrer revolutionären Tätigkeit zu sammeln und zu kommentieren.

Vor dem ersten Weltkrieg erschienen außerdem die von Karl Kautsky herausgegebenen „Theorien über den Mehrwert" von Marx, eine vierbändige Ausgabe des Briefwechsels zwischen Marx und Engels, die Briefe von Marx und Engels an Friedrich Adolph Sorge, Marx' Briefe an Louis Kugelmann u.a. Besondere Bedeutung hatte die Herausgabe des Briefwechsels zwischen den Begründern des Marxismus. Er wurde jedoch von Eduard Bernstein, der bereits zum Ideologen des Revisionismus geworden war, unzulänglich ediert. Von den Briefen, die sich im Archiv der deutschen Sozialdemokratie befanden, wurden etwa 150 nicht in die Ausgabe aufgenommen und eine Reihe von Briefen wurde nur gekürzt wiedergegeben. Die Vorworte und die Erläuterungen waren oberflächlich und teilweise falsch. Während des ersten Weltkrieges erschienen zwei von D. B. Rjasanow vorbereitete Bände mit Artikeln von Marx und Engels aus den fünfziger Jahren, hauptsächlich aus der "New-York Daily Tribune”.

Ungeachtet ihrer großen Bedeutung machten alle diese Veröffentlichungen nur einen geringen Teil des literarischen Erbes der Begründer des Marxismus zugänglich. Je weiter sich die Mehrheit der SPD-Führer vom Marxismus entfernte, um so geringer wurde ihr Interesse an einer systematischen Herausgabe der Schriften von Marx und Engels.

Eine neue Etappe bei der Veröffentlichung des literarischen Erbes der Begründer des Marxismus wurde durch den Sieg der Großen Sozialistischen Oktoberrevolution und die Errichtung der Sowjetmacht eingeleitet. Die Kommunistische Partei, die Sowjetregierung und Lenin persönlich betrach- 
teten die umfassende Publikation des literarischen Erbes von Marx und Engels als eine der wichtigsten ideologischen Aufgaben und als ihre internationalistische Pflicht gegenüber der Arbeiterklasse der ganzen Welt. Ein wichtiger Schritt zur erfolgreichen Lösung dieser Aufgabe war die Bildung einer speziellen Institution, der die Aufgabe übertragen wurde, für die Herausgabe der Werke der Begründer des Marxismus die entsprechende dokumentarische Basis zu schaffen und andere notwendige Vorbereitungsarbeiten in Angriff zu nehmen. Im Januar 1921 wurde deshalb auf Initiative W.I. Lenins und auf Beschluß des Zentralkomitees der Kommunistischen Partei Rußlands (Bolschewiki) das Marx-Engels-Institut (das später mit dem Lenin-Institut zum Marx-Engels-Lenin-Institut vereinigt wurde) gegründet. Dieses Institut begann mit der systematischen Sammlung der veröffentlichten Werke von Marx und Engels, ihrer Handschriften und Briefe sowie der an sie gerichteten Briefe verschiedener Korrespondenten. Zahlreiche biographische Materialien, aber auch Quellen und Literatur zur Geschichte der Arbeiterbewegung und des wissenschaftlichen Sozialismus, Periodica, an denen die Begründer des Marxismus mitgearbeitet hatten, u. a. m. konnten zusammengetragen werden. Bereits gegen Ende der zwanziger Jahre verfügte das Institut über die umfangreichste Sammlung des literarischen Erbes von Marx und Engels in der Welt und entfaltete eine vielseitige Publikationstätigkeit, die weite internationale Anerkennung fand.

Das Marx-Engels-Lenin-Institut veröffentlichte erstmals solche wichtigen Arbeiten der Begründer des Marxismus wie den vollständigen Text der "Deutschen Ideologie" und der „Dialektik der Natur”, die „OKonomischphilosophischen Manuskripte" und andere Dokumente. Ab 1924 begann das Institut auf Beschluß des XIII. Parteitags der KPR(B) mit der Vorbereitung der ersten vielbändigen Ausgaben der Werke von Marx und Engels sowohl in russischer Sprache als auch in den Originalsprachen. Der V.Kongreß der Kommunistischen Internationale begrüßte begeistert diesen Beschluß und rief alle kommunistischen Parteien der Welt auf, dem Marx-EngelsInstitut jede mögliche Unterstützung zu erweisen.

Die erste Werkausgabe in russischer Sprache begann 1928 zu erscheinen und wurde im wesentlichen 1941 abgeschlossen. Sie bestand aus 28 Bänden (in 33 Büchern). Bis zum Erscheinen der zweiten Ausgabe der Werke von Marx und Engels in russischer Sprache blieb sie die einzige und vollständigste Sammlung der Werke der Begründer des Marxismus. Sie enthielt etwa 1250 Werke und ca. 3300 Briefe, von denen 460 Werke und etwa 800 Briefe bis dahin der Öffentlichkeit unbekannt waren.

Die Gesamtausgabe der Werke von Marx und Engels in den Originalsprachen (MEGA), die zur gleichen Zeit vom Marx-Engels-Institut zunächst 
unter der Leitung von D. B. Rjasanow und später von W.W. Adoratski in Angriff genommen wurde, sollte alle bis zum damaligen Zeitpunkt bekannten Werke von Marx und Engels, ihren handschriftlichen Nachlaß, darunter die unvollendet gebliebenen Arbeiten, aber auch alle vorbereitenden Materialien enthalten: Entwürfe, Notizen, Exzerpte usw., teils vollständig, teils in Beschreibungen. In die MEGA sollten weiterhin alle erhalten gebliebenen Briefe der Begründer des Marxismus sowie ein Teil der Briefe dritter Personen an sie aufgenommen werden. An der Vorbereitung der MEGA nahmen neben den sowjetischen Mitarbeitern des Instituts auch Vertreter anderer kommunistischer Parteien teil, in erster Linie deutsche Kommunisten. Fortschrittliche Wissenschaftler mehrerer Länder unterstützten ebenfalls die Arbeit an dieser Ausgabe, indem sie dem Institut wichtiges Quellenmaterial zur Verfügung stellten. Bis zur Errichtung der faschistischen Diktatur in Deutschland wurden die Bände zunächst in Frankfurt am Main und später in Berlin gedruckt.

Der Plan für diese Ausgabe konnte nur zum Teil verwirklicht werden. In den Jahren 1927 bis 1935 erschienen 7 Bände der ersten Abteilung, die die Werke von Marx und Engels (außer dem ,'Kapital", das die zweite Abteilung bilden sollte) enthielt, 4 Bände der dritten Abteilung (Briefwechsel zwischen Marx und Engels) und ein gesonderter Band mit dem "Anti-Dühring" und der "Dialektik der Natur" von Engels. Außerdem wurde nach dem Typ dieser Ausgabe 1939-1941 erstmals Marx' ökonomisches Manuskript aus den Jahren 1857/1858 (, Grundrisse der Kritik der politischen Ökonomie. Rohentwurf 1857-1858') veröffentlicht. Alle diese MEGA-Bände fanden weltweite Verbreitung und Anerkennung.

Parallel zur Herausgabe der Werke von Karl Marx und Friedrich Engels erschien seit 1924 das "Marx-Engels-Archiv". Darin wurden neben wissenschaftlichen Artikeln und Mitteilungen viele handschriftlich überlieferte Arbeiten von Marx und Engels - zumeist erstmals - veröffentlicht. $A b$ 1931 änderte sich der Charakter des "Archivs". Fortan wurden hier ausschließlich Materialien aus der Feder der Begründer des Marxismus publiziert. Ein Teil davon wurde später in der ersten und zweiten Ausgabe der Werke wieder abgedruckt, einige bedeutende Arbeiten blieben jedoch nur im „Archiv" veröffentlicht.

Die Entstehung der sozialistischen Staatengemeinschaft und das gewaltige Anwachsen der fortschrittlichen Kräfte in allen Ländern im Ergebnis des Sieges der Sowjetunion und der mit ihr in der Antihitlerkoalition verbündeten Völker über den deutschen und italienischen Faschismus sowie den japanischen Militarismus im zweiten Weltkrieg eröffneten neue Möglichkeiten für die Verbreitung des Marxismus-Leninismus. Das Interesse an den Werken der Begründer des wissenschaftlichen Kommunismus 
wuchs außerordentlich. In den sozialistischen Ländern wurden spezielle wissenschaftliche Zentren zur Herausgabe der Werke von Marx, Engels und Lenin und zur Ausarbeitung der Geschichte der Arbeiterbewegung und des Marxismus-Leninismus geschaffen. Eine besondere Rolle bei der Herausgabe der Werke von Marx und Engels in ihrer Muttersprache spielte das Institut für Marxismus-Leninismus beim ZK der SED, das bei der Entdeckung, Sammlung und Edition von Handschriften und Drucken der Werke von Marx und Engels sowie von Materialien über ihr Leben und Wirken eine umfangreiche Arbeit leistet.

Vom Institut für Marxismus-Leninismus beim ZK der KPdSU wurde von 1955 bis 1966 die zweite Ausgabe der Werke von Karl Marx und Friedrich Engels in russischer Sprache veröffentlicht. Sie umfaßt 39 Bände (42 Bücher) und enthält rund 5500 Werke und Briefe der Begründer des Marxismus, womit der Umfang der ersten Ausgabe um fast 1000 Dokumente, darunter etwa 600 Briefe, übertroffen wurde. Durch intensive Forschungen konnte erstmalig die Autorschaft von Marx und Engels für eine große Anzahl publizistischer Arbeiten ermittelt werden. Es konnten zahlreiche Druckfehler und ungenaue Entzifferungen von Handschriften berichtigt sowie viele von Marx und Engels benutzte Quellen ausfindig gemacht werden. Die zweite Ausgabe ist mit einem umfangreichen wissenschaftlichen Apparat versehen, zu dem redaktionelle Vorworte, historische und textologische Anmerkungen, Erläuterungen zur Entstehungs- und Überlieferungsgeschichte einzelner Werke usw. gehören. Die wissenschaftliche Offentlichkeit schätzt diesen Apparat als einen bedeutenden Beitrag zur Ausarbeitung vieler wichtiger Probleme der Marx-Engels-Forschung, der Geschichte der internationalen Arbeiterbewegung und des wissenschaftlichen Kommunismus.

Die zweite russische Ausgabe diente als Grundlage für die 1968 vom Institut für Marxismus-Leninismus beim ZK der SED in deutscher Sprache fertiggestellten Marx-Engels-Werke (MEW) in 39 Bänden (41 Büchern) und einem Ergänzungsband (in zwei Büchern) mit frühen Schriften der Begründer des Marxismus. Fast zwei Drittel der in der Ausgabe enthaltenen Werke und Briefe wurden in Deutsch geschrieben und somit in der Originalsprache vorgelegt. Diese Werkausgabe fand daher eine außerordentlich große internationale Verbreitung.

Auf der Basis dieser beiden Ausgaben werden vielbändige Ausgaben in bulgarischer, japanischer, koreanischer, polnischer, rumänischer, serbokroatischer, tschechischer, ukrainischer, ungarischer und anderen Sprachen veröffentlicht.

Einen bedeutsamen Beitrag zur weiteren Veröffentlichung des literarischen Erbes der Begründer des Marxismus stellen elf Ergänzungsbände zur 
zweiten Werkausgabe in russischer Sprache (die Bände 40 bis 50) dar. Sie enthalten eine ganze Reihe bisher unveröffentlichter Manuskripte von Marx und Engels, Artikel und Briefe, die erst nach dem Erscheinen der zweiten Ausgabe aufgefunden wurden, sowie einige Arbeiten, die in die Bände 1 bis 39 nicht aufgenommen worden waren. Die Herausgabe dieser Ergänzungsbände wie auch der vorgesehenen Ergänzungsbände der Marx-Engels-Werke in der DDR erweitern die Möglichkeiten für neue Veröffentlichungen und für das Studium des literarischen Erbes von Marx und Engels bedeutend.

Das Institut für Marxismus-Leninismus beim ZK der KPdSU und der Moskauer Verlag „Progress” nahmen gemeinsam mit Verlagen der Kommunistischen Partei Großbritanniens und der Kommunistischen Partei der USA eine fünfzigbändige Ausgabe der Werke von Marx und Engels in englischer Sprache in Angriff. Diese Ausgabe wird die Materialien der zweiten russischen Ausgabe einschließlich der Ergänzungsbände enthalten, darunter in den letzten Jahren neu aufgefundene Werke und Briefe der Begründer des Marxismus. Für diese Ausgabe wird ebenfalls eine spezielle textologische Arbeit geleistet, insbesondere an den Schriften, die in englischer Sprache verfaßt wurden. Entsprechend der englischen Ausgabe begann der Verlag „Editori Riuniti” in Rom mit einer fünfzigbändigen Ausgabe der Werke von Marx und Engels in italienischer Sprache. Der Verlag "Éditions Sociales" in Paris gibt eine vollständige Ausgabe der Briefe in französischer Sprache heraus und bereitet gleichfalls eine Ausgabe sämtlicher Werke von Marx und Engels in französischer Sprache vor. Außerdem haben einige wissenschaftliche Institutionen - wie das Internationale Institut für Sozialgeschichte (Amsterdam), das Institut Feltrinelli (Mailand) u. a. - eine Reihe wichtiger wissenschaftlicher Einzelausgaben veröffentlicht, darunter den Briefwechsel von Marx und Engels mit einzelnen Persönlichkeiten.

Die umfangreiche Arbeit, die für alle genannten Ausgaben sowohl bei der Suche und Sammlung des literarischen Erbes der Begründer des Marxismus als auch bei der Textuntersuchung und wissenschaftlichen Kommentierung geleistet wurde, schafft wichtige Voraussetzungen, um das Vorhaben einer Gesamtausgabe der Werke von Karl Marx und Friedrich Engels in den Originalsprachen zu verwirklichen.

Die außerordentliche Bedeutung des theoretischen Erbes von Marx und Engels im geistigen Leben unserer Zeit, für den Kampf der Arbeiterklasse und aller fortschrittlichen Kräfte erfordert heute mehr denn je, ihre Werke 
in den vielfältigsten Formen zu verbreiten. Um den Voraussetzungen und Anforderungen unterschiedlicher Leserkreise gerecht werden zu können, sind verschiedene Typen von Marx-Engels-Editionen notwendig: Einzelveröffentlichungen, thematische Sammelbände, Auswahlausgaben und gesammelte Werke, Veröffentlichungen in den Originalsprachen und in Übersetzungen.

Eine besondere Bedeutung kommt der Veröffentlichung einer wissenschaftlichen Gesamtausgabe der Werke von Marx und Engels in den Originalsprachen zu. Sie soll für die weitere gründliche Erforschung der Geschichte und der Theorie des Marxismus sowie für andere Ausgaben von Werken der Begründer des wissenschaftlichen Kommunismus in allen Ländern und Sprachen eine feste Grundlage bieten. Diese spezielle und zugleich grundlegende Aufgabe bestimmt Charakter und Spezifik der Editionsprinzipien der Marx-Engels-Gesamtausgabe.

Die MEGA bietet das literarische Erbe von Marx und Engels - soweit es überliefert und zugänglich ist - vollständig dar. Zu den Werken, Artikeln und Briefen, die bereits in der zweiten russischen und der deutschen Werkausgabe enthalten sind, treten inzwischen neuentdeckte Arbeiten und Briefe hinzu. Ferner werden nunmehr auch alle Manuskripte und Entwürfe, Konspekte und Exzerpte, Marginalien und ähnliche Studienmaterialien von Marx und Engels veröffentlicht. Das gleiche gilt für Aufzeichnungen ihrer Reden und Gespräche, für Dokumente der demokratischen und Arbeiterbewegung, an deren Abfassung Marx und Engels beteiligt waren, und ähnliche Materialien. Darüber hinaus werden außer den Briefen von Marx und Engels auch die Briefe anderer Personen an sie und eine Reihe für die Marx-Engels-Forschung wichtiger Briefe Dritter untereinander aufgenommen. Allein die neu zu veröffentlichenden Materialien beanspruchen mehrere Dutzend Bände. Die MEGA vertieft und erweitert dadurch den Einblick in die theoretische Arbeit und den praktisch-politischen Kampf von Marx und Engels.

In der MEGA werden alle Texte in voller Übereinstimmung mit den Originalen und in deren jeweiliger Sprache veröffentlicht. Der Abdruck in der Originalsprache ermöglicht ein Maximum an Authentizität der Textwiedergabe, er erleichtert die Übersetzung der Werke von Marx und Engels und damit die Verbreitung ihrer Ideen. Er ermöglicht auch genauere Untersuchungen über die Entwicklung der Terminologie des Marxismus und das große sprachschöpferische Wirken seiner Begründer, die die Begriffswelt und den Wortschatz der revolutionären Arbeiterbewegung und der ganzen fortschrittlichen Menschheit nachhaltig beeinflußt haben.

Mit dem Vollständigkeitsprinzip und der Wiedergabe aller Texte in den Originalsprachen ist ein weiteres Charakteristikum der MEGA eng ver- 
bunden: Sie bietet das gesamte Werk von Marx und Engels in seiner historischen Entwicklung dar und dokumentiert dabei das Reifen aller Werke von der ersten Skizze bis zur Fassung letzter Hand, soweit es überliefert ist. Erstmals kann somit für jedes Werk jede beliebige von Marx und Engels stammende oder von ihnen autorisierte Fassung bzw. Übersetzung herangezogen, aber auch die Textentwicklung in ihrer Gesamtheit überblickt werden. Dadurch ermöglicht es die MEGA, sowohl die bereits veröffentlichten Werke von Marx und Engels tiefer zu verstehen als auch die erstmals zugänglich gemachten Arbeiten in das gesamte Schaffen der Begründer des Marxismus einzuordnen. Sie gibt einen Einblick in die Arbeitsmethoden von Marx und Engels, wie er bisher nicht gewonnen werden konnte, und dokumentiert die Besonderheiten sowie die Etappen der Entstehung und Entwicklung des Marxismus so umfassend wie möglich.

Schließlich wird in der MEGA das literarische Werk von Marx und Engels auf der Basis einer gründlichen textkritischen Analyse dargeboten und, soweit es für den wissenschaftlichen Benutzer erforderlich ist, eingehend und umfassend kommentiert.

Die historisch-kritische Marx-Engels-Gesamtausgabe wird etwa 100 Bände umfassen. Um die Bearbeitung und Benutzung zu erleichtern, ist diese große Ausgabe in Abteilungen gegliedert. Die Gliederung der MEGA in Abteilungen geht aus von den verschiedenen Formen des literarischen Schaffens von Marx und Engels, die unterschiedliche Wiedergabeformen erfordern.

Zunächst werden die Werke, Artikel, Entwürfe einerseits und die Briefe andererseits in eigenen Abteilungen angeordnet, wie das in allen vergleichbaren Editionen geschieht. „Das Kapital“ bildet eine selbständige Abteilung. Seine Entwürfe und Druckfassungen beanspruchen allein etwa 20 Textbücher. Der Leser erhält dadurch die Möglichkeit, den jahrzehntelangen Entstehungsprozeß des Hauptwerks von Marx im Zusammenhang zu verfolgen. In einer eigenen Abteilung werden schließlich die Exzerpte und Konspekte, Notizbücher, Randbemerkungen und Anstreichungen in Büchern angeordnet. Nur einige von ihnen lassen sich jeweils einem bestimmten Werk als Vorarbeit zuordnen; viele wurden von den Autoren für mehrere Arbeiten benutzt. Zudem spielt in diesen Materialien die Aneignung des vorgefundenen Gedankenmaterials gegenüber der Darlegung des eigenen Standpunktes von Marx und Engels eine wichtige, meist die dominierende Rolle, und dem müssen spezifische Editionsmethoden entsprechen.

Die MEGA ist also in vier Abteilungen gegliedert:

Erste Abteilung: Werke, Artikel, Entwürfe (mit Ausnahme des ,'Kapitals“), Zweite Abteilung: „Das Kapital“ und Vorarbeiten, 
Dritte Abteilung: Briefwechsel,

Vierte Abteilung: Exzerpte, Notizen, Marginalien.

Als Ergänzung werden in gesonderten Bänden der MEGA „Lebenszeugnisse" veröffentlicht, d.h. zeitgenössische Dokumente über Marx und Engels von hohem wissenschaftlichen Aussagewert, so Fotos und zeitgenössische Zeichnungen, die Marx und Engels, ihre Familienmitglieder und Kampfgefährten sowie ihre Wohn- und Wirkungsstätten abbilden; authentische Äußerungen von Zeitgenossen in Briefen, Artikeln, Tagebüchern, Berichten; zuverlässige Aussagen aus Akten von Zensur-, Gerichts-, Polizei- und anderen Behörden usw.

Zum Abschluß der Editionsarbeiten werden Register für die einzelnen Abteilungen bzw. für das Gesamtwerk die Ausgabe vervollständigen.

Innerhalb der vier Abteilungen der MEGA werden die Texte chronologisch geordnet. Da Marx und Engels zunächst unabhängig voneinander vom revolutionären Demokratismus zum Kommunismus und vom Idealismus zum Materialismus übergingen, werden ihre bis zu ihrem Zusammentreffen im August 1844 entstandenen Arbeiten und Briefe getrennt dargeboten; vom Beginn ihres gemeinsamen Schaffens an werden ihre Arbeiten jedoch in einer Chronologie gebracht. Für die chronologische Einordnung der einzelnen Texte ist das Datum der Abfassung, nicht das der Veröffentlichung maßgebend, da die MEGA vor allem die Entstehungsund Entwicklungsgeschichte des Marxismus dokumentiert. Die Bandeinteilung berücksichtigt die allgemeine Periodisierung der Geschichte des Marxismus und der internationalen Arbeiterbewegung sowie die wichtigsten Etappen im Leben von Marx und Engels. Innerhalb der dadurch gebildeten markanten Einschnitte muß jedoch dem Umfang des überlieferten Materials Rechnung getragen werden.

In den eigentlichen Textteilen der MEGA-Bände werden nur jene Texte wiedergegeben, die nachweisbar von Marx und Engels stammen, und zwar in Textfassungen, die von ihnen autorisiert wurden. Alle anderen Materialien werden in einem Anhang zum Textteil gebracht. Dazu gehören auch jene Arbeiten, für die eine Autorschaft von Marx und Engels anzunehmen, aber nicht zweifelsfrei nachzuweisen ist (Dubiosa), zumeist anonym veröffentlichte Artikel in Zeitungen und Zeitschriften.

Der wissenschaftliche Apparat zu den einzelnen Bänden, der im folgenden noch näher charakterisiert ist, wird getrennt vom Textteil gebunden, damit er parallel zu diesem gelesen werden kann. 
Die Erste Abteilung der MEGA enthält sämtliche Arbeiten von Marx und Engels, ausgenommen „Das Kapital" und die zu ihm gehörenden Manuskripte. Die Werke, Artikel und Entwürfe spiegeln die Entwicklung und den Ideenreichtum der von ihnen begründeten revolutionären Theorie und ihre Vereinigung mit der Arbeiterbewegung umfassend wider.

Obwohl gerade dieser wichtige Teil des Erbes von Marx und Engels in den vorliegenden Werkausgaben bereits weitgehend veröffentlicht wurde, bereichert die Erste Abteilung der MEGA die Marx-Engels-Forschung außerordentlich. Eine Reihe noch unveröffentlichter Entwürfe und Manuskripte sowie neu entdeckter Publikationen von Marx und Engels werden hier abgedruckt. Der wissenschaftliche Informationsgehalt wird auch dadurch erweitert, daß alle Werke in der Sprache der jeweiligen Originale und in allen autorisierten Fassungen dargeboten werden.

In der Ersten Abteilung werden Planskizzen, Entwürfe und Rohfassungen zu einer Reihe von Schriften und Artikeln zugänglich gemacht, die anschaulich die Genesis wichtiger Ideen des Marxismus zeigen und wertvolle Einblicke in die Arbeitsmethoden seiner Begründer geben. Wichtige Handschriften erfahren durch die detaillierte Darbietung der innerhandschriftlichen Textentwicklung eine für die Forschung aussagekräftigere Wiedergabe. Das betrifft ganz besonders die „Okonomisch-philosophischen Manuskripte", die "Deutsche Ideologie" und die "Dialektik der Natur".

Im Vergleich zu anderen Ausgaben erhöht sich die Zahl der aufgenommenen Presseartikel von Marx und Engels dadurch, daß die Zeitungen und Zeitschriften, an denen sie mitarbeiteten, erneut nach Arbeiten von ihnen durchforscht werden. Zudem gibt die MEGA die Artikel in allen von Marx und Engels autorisierten Fassungen wieder. Viele Artikel von Marx und Engels erschienen beispielsweise gleichzeitig in der amerikanischen Zeitung "New-York Daily Tribune” und in europäischen Presseorganen im „People's Paper” oder in der „Neuen Oder-Zeitung" - und bisweilen außerdem später als Einzelausgaben. In einigen Fällen nahmen die Autoren für die verschiedenen Abdrucke erhebliche Veränderungen oder Ergänzungen vor, entsprechend der politischen Richtung des einen oder des anderen Presseorgans oder Verlages.

Vor allem aber werden die großen Werke von Marx und Engels, die oft mehrere Ausgaben - darunter Übersetzungen - erlebten, in denen die Verfasser die Darstellung verbesserten und nicht selten neue theoretische Erkenntnisse einarbeiteten, erstmals in allen autorisierten Fassungen zugänglich gemacht. Werke wie "Das Elend der Philosophie", "Manifest der Kommunistischen Partei", „Der Bürgerkrieg in Frankreich", „Die Ent- 
wicklung des Sozialismus von der Utopie zur Wissenschaft", „Der Ursprung der Familie, des Privateigentums und des Staats" können in der Ersten Abteilung der MEGA mit ihrer gesamten Textentwicklung studiert werden. Von der aus Marx' Feder stammenden Adresse des Generalrats der Internationalen Arbeiterassoziation "Der Bürgerkrieg in Frankreich" werden beispielsweise - außer den Entwürfen - sowohl die englische Originalfassung mit ihren Varianten wie die von Engels stammende Übersetzung ins Deutsche mit ihren Varianten und dazu noch die von Marx betreute und teilweise redigierte französische Übersetzung von 1872 abgedruckt. Von Engels' Arbeit „Der Ursprung der Familie, des Privateigentums und des Staats" werden sowohl die Ausgabe von 1884 als auch die Varianten der Ausgabe von 1891 wiedergegeben. Große Aufmerksamkeit verdienen die Publikationen von Marx' Schriften, die nach seinem Tode von Engels besorgt wurden, so dessen Ausgabe von "Lohnarbeit und Kapital”. Sie wird im Textteil in der Fassung von 1849, nach der Veröffentlichung in der „Neuen Rheinischen Zeitung", dargeboten, während im Variantenverzeichnis die Fassung von 1891 wiedergegeben wird, in der Engels einige Stellen ergänzt und terminologisch dem „Kapital” angeglichen hat.

Besondere Bedeutung kommt den von Marx und Engels angefertigten oder redigierten Übersetzungen einiger ihrer Werke zu. Sie widerspiegeln den Prozeß der Ausarbeitung der marxistischen Terminologie, lassen Rückschlüsse auf den Grad der Verbreitung des Marxismus in den einzelnen Ländern zu und bereichern das Wissen vom Einfluß der Ideen des wissenschaftlichen Kommunismus auf die Entwicklung der internationalen Arbeiterbewegung wesentlich. Sie dokumentieren eine wichtige Seite des Schaffens von Marx und Engels, die den Übersetzungen ihrer Schriften und der von ihnen verfaßten Dokumente der Arbeiterbewegung große Bedeutung beimaßen.

In der Ersten Abteilung der MEGA werden alle von Marx und Engels selbst angefertigten oder redigierten Übersetzungen wiedergegeben, darunter Marx' deutsche Übersetzung der zweiten Adresse des Generalrats der Internationalen Arbeiterassoziation über den Deutsch-Französischen Krieg, die von Engels 1885 redigierte deutsche Übersetzung von Marx' "Misere de la philosophie" und die von ihm durchgesehene englische Übersetzung seiner Arbeit „Die Entwicklung des Sozialismus von der Utopie zur Wissenschaft" von 1892. Darüber hinaus werden auch Übersetzungen berücksichtigt, die sie nicht selbst anfertigten oder redigierten, aber autorisierten. Sie werden im Anhang zu den Textteilen der Ersten Abteilung ganz oder teilweise abgedruckt oder zumindest beschrieben.

Vollständig werden in die Erste Abteilung der MEGA auch alle Aufzeichnungen und Notizen von Marx und Engels zuverschiedenen Ereignissen 
in der Arbeiterbewegung aufgenommen. Das gleiche gilt für Wiedergaben ihrer Reden und Diskussionsbeiträge auf Versammlungen und Beratungen. Solche Dokumente widerspiegeln deutlich die Strategie und Taktik der Begründer des wissenschaftlichen Kommunismus und den stetig zunehmenden Einfluß des Marxismus in der Arbeiterbewegung; außerdem enthalten sie wichtige theoretische und politische Aussagen.

Schließlich ist hervorzuheben, daß im Anhang zum Textteil der Bände der Ersten Abteilung auch Arbeiten von Kampfgefährten und Familienangehörigen, die unter unmittelbarer Beteiligung von Marx und Engels entstanden oder von ihnen redigiert wurden, vollständig, auszugsweise oder beschreibend wiedergegeben werden.

Die Zweite Abteilung der MEGA ist dem Hauptwerk von Karl Marx, dem "Kapital", gewidmet. Aufnahme finden hier die ökonomischen Manuskripte der füntziger Jahre, Marx' Arbeit "Zur Kritik der politischen Okonomie" (1859), alle vorhergehenden Manuskripte für "Das Kapital" sowie die autorisierten Ausgaben aller drei Bände. Die Zweite Abteilung soll ein vollständiges Bild vom Verlauf und Charakter der jahrzehntelangen Arbeit von Marx an diesem Werk vermitteln und zugleich die große Leistung dokumentieren, die Engels nach Marx'. Tod bei der Bearbeitung und Herausgabe des zweiten und dritten Bandes des "Kapitals" vollbrachte.

Da die Zweite Abteilung nur die langjährige Geschichte des "Kapitals", nicht aber die Entstehung und Entwicklung der ökonomischen Lehre von Marx und Engels überhaupt darzustellen hat, beginnt diese Abteilung mit jener neuen Etappe der ökonomischen Forschungen von Marx, die in den fünfziger Jahren einsetzte, als die Struktur des "Kapitals" schon unmittelbar Gestalt annahm.

Die Zweite Abteilung wird eröffnet mit dem umfangreichen Manuskript aus den Jahren 1857/1858 - bekannt unter dem Titel "Grundrisse der Kritik der politischen Okonomie" -, das man als ersten Rohentwurf des ",Kapitals" betrachten kann. Es gibt Einblick in Marx' Schaffensprozeß und macht es möglich, die Ausarbeitung der Grundlagen seiner ökonomischen Theorie Schritt für Schritt zu verfolgen. Die "Grundrisse" widerspiegeln die Ergebnisse fünfzehnjähriger Forschungen auf dem Gebiet der politischen Ökonomie. Hier hat die Ausarbeitung der ökonomischen Lehre von Marx nicht nur in den Grundzügen, sondern auch in wesentlichen Details erstmals Gestalt angenommen. Im ökonomischen Manuskript von 1857/1858 wurde erstmals die Marxsche Mehrwerttheorie entwickelt, die zusammen 
mit dem von Marx und Engels in den vierziger Jahren ausgearbeiteten historischen Materialismus den Sozialismus aus einer Utopie in eine Wissenschaft verwandelte.

Es folgt dann Marx' Arbeit „Zur Kritik der Politischen Oekonomie. Erstes Heft" (1859). Zusammen mit diesem Werk werden das erhalten gebliebene Manuskript seines Entwurfs sowie verschiedene Vorarbeiten aus den Jahren 1859 bis 1861 (Planentwürfe, detaillierte Verzeichnisse u.ä.) dargeboten.

Einen weiteren Band der Zweiten Abteilung (in 6 Büchern) füllt das von 1861 bis 1863 verfaßte umfangreiche Manuskript in 23 Heften, das eine mehr oder weniger systematische, wenn auch noch rohe und unvollendete Ausarbeitung des gesamten „Kapitals" darstellt. Darin sind Fragen behandelt, die alle drei theoretischen Bände des „Kapitals" betreffen. Der Text jener Hefte, in denen vor allem Fragen der Verwandlung von Geld in Kapital und der Produktion des absoluten und relativen Mehrwerts untersucht werden, wurde erstmalig 1973 in russischer Sprache veröffentlicht. Der umfangreichste und am vollständigsten ausgearbeitete Teil dieses Manuskripts sind die „Theorien über den Mehrwert", die den vierten und letzten Band des „Kapitals" bilden sollten; es ist die einzige Fassung des vierten Bandes. Die "Theorien über den Mehrwert" werden in der MEGA als Bestandteil des Manuskripts aus den Jahren 1861 bis 1863 veröffentlicht.

Der nächste Schritt zur Ausarbeitung seiner ökonomischen Lehre und zur Vorbereitung des „Kapitals" war das Manuskript, das Marx in den Jahren 1863 bis 1865 niederschrieb. Es wurde schon von vornherein in den drei Teilen des „Kapitals" abgefaßt. Vom Manuskript des ersten Bandes des „Kapitals" ist lediglich das sechste Kapitel, „Resultate des unmittelbaren Produktionsprozesses", überliefert, das in die endgültige Fassung des ersten Bandes nicht aufgenommen wurde. Es wurde 1933 vom Institut für Marxismus-Leninismus beim ZK der KPdSU deutsch und russisch im "Marx-Engels-Archiv" veröffentlicht.

Das Manuskript von 1863-1865 enthält weiterhin die erste Fassung des zweiten Bandes des „Kapitals”. Engels hat sie später bei der Bearbeitung dieses Bandes nicht benutzt, sie wurde bisher nur 1974 in russischer Sprache veröffentlicht. Schließlich enthält dieses Manuskript die einzige von Marx hinterlassene Fassung des dritten Bandes des "Kapitals". Auf seiner Grundlage gab Engels 1894 unter Berücksichtigung der späteren Einfügungen und Ergänzungen von Marx und mit eigenen Zusätzen diesen Band heraus. In der MEGA wird das Manuskript von 1863-1865 vollständig in der von Marx hinterlassenen Form veröffentlicht.

Der erste Band des "Kapitals" wird in der MEGA mehrere Bände umfassen. Außer der ersten deutschen Ausgabe von 1867 werden spätere 
autorisierte Ausgaben, die wichtige Änderungen und Ergänzungen enthalten, vollständig abgedruckt. Dazu gehört die zweite deutsche Ausgabe von 1872, die viele Änderungen und Ergänzungen von Marx aufweist und auch in der Struktur wesentlich verändert wurde. Ein Band wird die französische Ausgabe von 1872-1875 darbieten. In ihr hat Marx viele Änderungen und Ergänzungen vorgenommen, von denen nur ein Teil in der dritten und vierten deutschen Ausgabe berücksichtigt wurde. Ein weiterer Band wird die englische Ausgabe von 1887 aufnehmen. Sie wurde von Samuel Moore und Edward Aveling bearbeitet und von Friedrich Engels durchgesehen und redigiert. Von der dritten deutschen Ausgabe werden die Varianten im Apparat dargeboten. Vollständig wird wiederum die von Engels redigierte vierte deutsche Ausgabe des ersten Bandes des , Kapitals" (1890) abgedruckt, die heute vorwiegend als Editionsgrundlage dient.

Die MEGA wird weiterhin alle überlieferten Manuskripte des zweiten Bandes des „Kapitals" sowie die Druckfassung der von Engels 1885 besorgten Ausgabe enthalten. Als Varianten erscheinen die Änderungen von Engels, die er in der zweiten Auflage des zweiten Bandes von 1893 vorgenommen hat.

Von den Vorarbeiten zum dritten Band des "Kapitals" blieben außer der bereits erwähnten Fassung, die ein Teil des Manuskripts von 1863-1865 ist, noch einige Entwürfe zu einzelnen Kapiteln erhalten, darunter das unveröffentlichte Manuskript „Das Verhältnis der Mehrwertrate zur Profitrate, mathematisch behandelt". Alle diese Materialien werden zusammen mit verschiedenen Manuskripten von Engels, die während seiner redaktionellen Tätigkeit am dritten Band entstanden, in der Zweiten Abteilung wiedergegeben. Der dritte Band des „Kapitals", wie ihn Engels 1894 herausgegeben hat, beschließt diese Abteilung der MEGA.

\section{VI}

In der Dritten Abteilung der MEGA wird der Briefwechsel von Karl Marx und Friedrich Engels veröffentlicht. Der Briefnachlaß der Begründer des wissenschaftlichen Kommunismus widerspiegelt anschaulich und umfassend die wichtigsten Etappen in der Herausbildung und Entwicklung des Marxismus und der internationalen Arbeiterbewegung. Er ergänzt den Inhalt ihrer Werke und dokumentiert in spezifischer Form die Wesensmerkmale des Marxismus - seinen schöpferischen Charakter, die Verbindung der revolutionären Theorie mit der revolutionären Praxis, die untrennbare Verbindung der Lehre von Marx und Engels mit dem Klassenkampf des Proletariats. 
Außerordentlich groß ist die biographische Bedeutung dieses Teils des Nachlasses. Die Briefe ermöglichen es, die wichtigsten Etappen des Lebens von Marx und Engels sowie die Entstehungsgeschichte ihrer Werke zu verfolgen, sie geben Aufschluß über eine Reihe wenig untersuchter Seiten ihrer politischen, organisatorischen und publizistischen Tätigkeit. Der Briefwechsel widerspiegelt die schwierigen Bedingungen, unter denen Marx und Engels lebten und wirkten, 2. B. die ständigen Verfolgungen seitens reaktionärer Regierungen, unter denen sie zu leiden hatten. Die Briefe sind ein lebendiges Zeugnis von der selbstlosen Freundschaft, die Marx, Engels und ihre engsten Mitkämpfer miteinander verband.

In der Dritten Abteilung der MEGA wird die Publikation der Korrespondenz von Marx und Engels nach mehreren Richtungen hin erweitert und vertieft.

Im Unterschied zu allen bisherigen Ausgaben der Werke werden erstmals alle Briefe von Marx und Engels untereinander wie auch an dritte Personen in einer einheitlichen chronologischen Reihenfolge veröffentlicht.

Von großer Bedeutung ist die Veröffentlichung der Briefe an Marx und Engels im Anhang zu den jeweiligen Bänden. Diese Dokumente sind zum vollen Verständnis ihrer eigenen Briefe unumgänglich und bieten für die Erforschung des Lebens und Wirkens von Marx und Engels und für das Studium der Geschichte des Marxismus und der internationalen Arbeiterbewegung wichtiges Material. In vielen Briefen an die Begründer des Marxismus werden Briefe aus deren Feder erwähnt, wiedergegeben oder zitiert, über deren Inhalt und Verbleib sonst nichts bekannt ist. Diese Briefe ermöglichen es, die Lücken im überlieferten Briefwechsel von Marx und Engels in gewissem Maß zu schließen. Dies trifft insbesondere für die frühe Periode (Ende der dreißiger/Anfang der vierziger Jahre) zu. Aus dieser Zeit sind nur einzelne Briefe von Marx überliefert, und lediglich aus den Antwortbriefen seiner Freunde und ihm nahestehender Personen haben wir vom Inhalt der verlorengegangenen oder bisher nicht aufgefundenen Briefe von Marx Kenntnis. Diese Materialien werden noch ergänzt durch Briefe dritter Personen untereinander, in denen der Inhalt nicht erhalten gebliebener Briefe von Marx und Engels wiedergegeben wird oder die in ihrem Auftrag geschrieben wurden; sie werden in einem gesonderten Teil des Anhangs dargeboten.

Zahlreiche Briefe dritter Personen sind eine wichtige und mitunter die einzige Quelle für biographische Angaben über Marx und Engels. Besonders wertvoll sind in dieser Hinsicht Briefe von Familienangehörigen, Verwandten und engen Freunden an die Begründer des Marxismus, denn sie enthalten oft wertvolle Mitteilungen über geplante Arbeiten, über die sonst nichts bekannt ist, sowie zur Entstehungsgeschichte ihrer Werke, 
Urteile über Arbeiten von Marx und Engels, Informationen über deren Veröffentlichung und Propagierung, die den Grad der Verbreitung und des Einflusses der marxistischen Ideen in vielen Ländern widerspiegeln.

Zu den Korrespondenzpartnern von Marx und Engels gehörten ihre Kampfgefährten, bedeutende Führer der internationalen Arbeiterbewegung, vor allem des Bundes der Kommunisten und der I. Internationale, sowie Vertreter von sozialistischen und Arbeiterparteien, Führer der revolutionärdemokratischen Bewegung und fortschrittliche Gelehrte in vielen Ländern : Victor Adler, P. W. Annenkow, August Bebel, Johann Philipp Becker, Wilhelm Bracke, N.F. Danielson, Eugène Dupont, Johann Georg Eccarius, Jules Guesde, George Julian Harney, Heinrich Heine, Ernest Charles Jones, Karl Kautsky, Paul Lafargue, P. L. Lawrow, Friedrich Leßner, Wilhelm Liebknecht, G. A. Lopatin, G.W. Plechanow, W. I. Sassulitsch, Friedrich Adolph Sorge, Joseph Weydemeyer, Wilhelm Wolff und viele andere. Ihre Briefe vermitteln eine Vorstellung von der herausragenden Rolle von Marx und Engels in der Arbeiterbewegung und von ihrem jahrelangen Kampf für die Schaffung und Festigung proletarischer Parteien. Viele Briefe von Arbeitern und Arbeiterorganisationen mehrerer Länder an Marx und Engels zeugen von der Liebe und Achtung gegenüber diesen beiden Führern des internationalen Proletariats.

In den Bänden der Dritten Abteilung werden auch die Widmungen von Marx und Engels in Büchern und auf Photographien publiziert, die ihre vielseitigen Beziehungen zu hervorragenden Persönlichkeiten ihrer Zeit widerspiegeln.

\section{VII}

In der Vierten Abteilung der MEGA werden erstmals alle überlieferten Exzerpte, Konspekte, Notizbücher und Marginalien von Marx und Engels veröffentlicht.

Einige Exzerpte und Konspekte von Marx und Engels wurden bereits in der Ersten Abteilung der ersten, unvollendeten MEGA beschrieben und auszugsweise wiedergegeben. Ein anderer Teil von ihnen wurde vom Institut für Marxismus-Leninismus beim ZK der KPdSU im „,Marx-EngelsArchiv" und in einzelnen Sammelbänden veröffentlicht. Diese oft fragmentarischen Publikationen vermittelten jedoch keine vollständige Vorstellung vom Charakter und Inhalt dieses wichtigen Teils des literarischen Nachlasses von Marx und Engels.

Die Exzerpte und Konspekte in Deutsch, Englisch, Französisch, Russisch, Italienisch, Latein, Griechisch und anderen Sprachen, die den Hauptinhalt der Vierten Abteilung bilden, sind außerordentlich umfangreich und ihrem 
Inhalt nach sehr mannigfaltig. Die Exzerpte und Konspekte von Marx und Engels enthalten eine Fülle von Material über die sozialökonomische und politische Geschichte mehrerer Völker und Epochen, über die Geschichte der sozialistischen Lehren, der Arbeiterbewegung, der internationalen Beziehungen und der Diplomatie, der Kriegskunst und andere Wissensgebiete. Sehr umfangreich und äußerst interessant sind die zahlreichen Exzerpte von Marx und Engels zu Fragen der politischen Okonomie. Eine Reihe von Exzerpten und Konspekten behandelt Fragen der Philologie und der Linguistik, der Religion, der Kunst und Literatur sowie der Naturwissenschaften. Eine besondere Gruppe ist politischen Ereignissen gewidmet, deren Zeitgenossen Marx und Engels waren.

Einen wichtigen Teil der nicht veröffentlichten handschriftlichen Bemerkungen von Marx stellen seine zahlreichen Notizbücher dar. Die 17 überlieferten Notizbücher von Marx aus den Jahren 1844 bis 1881 widerspiegeln verschiedene Seiten seiner Tätigkeit als Wissenschaftler und als Revolutionär. Sie enthalten kurze Aufzeichnungen von einzelnen Gedanken, knappe Entwürfe einiger Arbeiten, manchmal auch vollständige Dokumente wie z. B. die „Thesen über Feuerbach" oder die Resolution des Generalrats der I. Internationale über den Konflikt in den Pariser Sektionen, Briefentwürfe, Tagebuchaufzeichnungen, Angaben über gelesene Bücher usw. Die Notizbücher werden ebenso wie die Exzerpthefte vollständig wiedergegeben, einschließlich jener in ihnen enthaltenen Dokumente, Entwürfe von Artikeln oder Briefen usw., die auch in den entsprechenden Bänden der Ersten und Dritten Abteilung erscheinen.

Von großem Interesse sind die vielfältigen Randbemerkungen von Marx und Engels in den Büchern, die sie lasen. Diese Marginalien werden im Rahmen der Vierten Abteilung der MEGA in gesonderten Bänden wiedergegeben, die größere Zeitabschnitte im Leben und Wirken von Marx und Engels umfassen. Wie die Randbemerkungen, so werden auch die Anstreichungen in Büchern in angemessener Form veröffentlicht (vollständige oder teilweise Wiedergabe, detaillierte oder summarische Beschreibung).

In ihrer Gesamtheit illustrieren die Materialien der Vierten Abteilung anschaulich die Methoden der schöpferischen wissenschaftlichen Arbeit von Marx und Engels. Sie gewähren dem Leser Einblick in die Werkstatt und den Schaffensprozeß der Begründer des wissenschaftlichen Kommunismus. Viele dieser Materialien enthalten umfangreiche kritische Kommentare, andere sind nur mit einzelnen Bemerkungen von Marx und Engels versehen, für weitere ist die Anordnung und Auswahl des Materials charakteristisch, die den Gedankengang von Marx und Engels erhellt und den Blickwinkel deutlich macht, unter dem sie an die betreffende Frage herangingen. 
Ein Vergleich der Materialien der Vierten Abteilung mit den vollendeten Werken von Marx und Engels über analoge Probleme ermöglicht es, die Entstehung und Entwicklung einer Reihe wichtiger Ideen zu verfolgen. Die Exzerpte und Konspekte enthalten auch Gedanken, die in den vollendeten Werken der Begründer des wissenschaftlichen Kommunismus keine weitere Entwicklung erfuhren. Eine große Gruppe dieser Materialien fertigten Marx und Engels für Arbeiten an, die aus verschiedenen Gründen unvollendet blieben, von einigen ihrer Vorhaben und Pläne sind wir nur durch Exzerpte und Konspekte unterrichtet. Dazu gehören Marx' Exzerpte zur Geschichte der bürgerlichen Revolutionen und der nationalen Befreiungsbewegung in Spanien in der ersten Hälfte des 19. Jahrhunderts, die Exzerpte und Konspekte zur Geschichte der Urgesellschaft und des Gemeindewesens, zur ökonomischen Entwicklung in den USA und in Rußland nach der Reform von 1861, Engels' Exzerpte zur Geschichte Irlands usw.

Die Texte der Vierten Abteilung der MEGA stellen einen integrierenden Bestandteil des literarischen Nachlasses der Begründer des wissenschaftlichen Kommunismus dar. Sie sind eine einzigartige Quelle zum Studium des Entstehungs- und Entwicklungsprozesses der marxistischen Theorie und ihrer Bestandteile; in einigen Fällen ermöglichen sie es, die Besonderheiten dieses Prozesses vollständiger wiederzugeben, als es an $\mathrm{Hand}$ der veröffentlichten Schriften bisher möglich war. Zugleich widerspiegeln die Dokumente in den Bänden der Vierten Abteilung die ganze Universalität der wissenschaftlichen Interessen von Marx und Engels. Sie sind ein überzeugender Beweis dafür, daß der Marxismus auf der Grundlage einer kritischen Verarbeitung des Besten entstand, was die Wissenschaft bis dahin geschaffen hatte.

\section{VIII}

Der Wert der MEGA besteht nicht allein darin, daß sie das literarische Erbe von Marx und Engels erstmals vollständig zugänglich macht, sondern ergibt sich auch aus der Art und Weise, in der hier die Texte dargeboten werden.

Für eine Reihe von Aufgaben der Forschung und Edition ist die MEGA schon deshalb die einzige verwendbare Quellengrundlage, weil in ihr die Textwiedergabe getreu den originalen Handschriften und autorisierten Drucken in den Originalsprachen erfolgt. Die Rechtschreibung und Zeichensetzung wird in den Texten nicht modernisiert und nicht vereinheitlicht. Das Prinzip der größtmöglichen Übereinstimmung mit dem Original 
schließt eine kritische Textdurchsicht zur Beseitigung eindeutiger Druckund Schreibfehler ein. Sie erfolgt unter Heranziehung aller von Marx und Engels autorisierten Fassungen ihrer Werke, wobei nur äußerst behutsam und unter genauer Rechenschaftslegung vor dem Leser in die Autortexte eingegriffen wird.

Der originalgetreuen Wiedergabe der Handschriften von Marx und Engels wird besondere Aufmerksamkeit gewidmet. Unvollendete Manuskripte und Rohentwürfe werden in jenem Bearbeitungsstadium dargeboten, in dem sie die Autoren hinterlassen haben. Umstellungen, Einordnungen usw. finden in der Regel nur dort statt, wo sie die Autoren selbst vorgesehen haben. In Einzelfällen wird es erforderlich sein, Exkurse, Nachträge u.ä., die den fortlaufenden Text unterbrechen, an einer anderen Stelle wiederzugeben, die ihrem Inhalt und Charakter besser entspricht. Jede solche Veränderung in der Textanordnung wird nachgewiesen und begründet.

Im Interesse einer besseren Lesbarkeit der dargebotenen Texte werden die zahlreichen Kürzel, Abkürzungen und Verkürzungen, die die beiden Klassiker in ihren Manuskripten anwandten, beim Abdruck weitgehend aufgelöst, soweit dies mit ausreichender Sicherheit möglich ist. Wo es das Verständnis großer und wenig gegliederter Manuskripte gebietet, sind Zwischenüberschriften und Absätze eingefügt, die wie alle vorgenommenen Ergänzungen deutlich als von der Redaktion stammend gekennzeichnet sind. Bei der Darbietung von Exzerpten werden die von Marx und Engels stammenden Bemerkungen durch halbfetten Druck von den exzerpierten Quellentexten abgehoben und bei den letzteren durch besondere Zeichen alle wörtlich übernommenen Zitate von sinngemäß wiedergegebenen Passagen unterschieden. Dadurch treten die verschiedenen Stadien der Aneignung des vorgefundenen Gedankenmaterials durch Marx und Engels deutlich hervor.

Ein Hauptziel der Textdarbietung in der MEGA besteht darin, die Genesis der einzelnen Arbeiten mit Hilfe moderner Editionsmethoden vollständig und übersichtlich zu dokumentieren. Die Dokumentation der Textentwicklung ist für die Erschließung des Lebenswerkes der Begründer des Marxismus von außerordentlicher Bedeutung. Viele Werke von Marx und Engels entstanden in einem längeren, komplizierten Schaffensprozeß, der sich in mehreren Entwürfen und Druckfassungen niederschlug. Die in ihnen enthaltenen Erkenntnisse können um so besser verstanden werden, je klarer ihre Erarbeitung zu verfolgen ist, denn der Prozeß der ständigen Weiterentwicklung und Vervollkommnung der wissenschaftlichen Theorie der Arbeiterklasse durch Marx und Engels manifestierte sich nicht nur im Entstehen neuer Arbeiten, sondern auch in der Überarbeitung ihrer Werke.

Bei der Dokumentation dieser Textveränderungen bilden Textteil und 
Variantenverzeichnis eine Einheit. Wie in der ersten MEGA, aber im Unterschied zu den Studienausgaben, wird dem vollständigen Abdruck der Texte eine frühe Fassung zugrunde gelegt, also in der Regel die Handschrift oder der Erstdruck. Die weiteren Fassungen werden - auf die abweichenden Stellen verkürzt - im Variantenverzeichnis wiedergegeben, soweit sie nicht so starke Umformungen erfahren haben, daß sie im Textteil nochmals vollständig abzudrucken sind. Das Variantenverzeichnis ist somit ein dem Edierten Text prinzipiell gleichrangiger Teil der Darbietung der Textentwicklung. Die hier wiedergegebenen Werkfassungen werden daher auch in gleicher Weise wissenschaftlich kommentiert wie der Edierte Text.

Die Gestaltung des Variantenverzeichnisses der MEGA wird bestimmt durch seine Hauptfunktion, die Entwicklung der Texte darzustellen. Darum werden alle redaktionellen Korrekturen von den Varianten gesondert und in eigenen Verzeichnissen aufgeführt. Zur Entlastung der Variantenverzeichnisse werden weiterhin die Sinngebung nicht berührende Veränderungen der Orthographie und Interpunktion und darüber hinaus bei innerhandschriftlichen Textentwicklungen bloße Richtigstellungen von stilistischen und grammatikalischen Versehen, Schreibansätze, Textabbrechungen oder ähnliche kleinere Veränderungen, die weder die inhaltliche Aussage verändern noch den Stil wesentlich modifizieren, nicht im einzelnen verzeichnet, sondern generalisierend in den Zeugenbeschreibungen mitgeteilt. Als Varianten erscheinen also von Marx und Engels vorgenommene oder veranlaßte Textveränderungen, die den Text inhaltlich oder stilistisch durch Erweiterungen, Verkürzungen, Ersetzungen oder Umstellungen weiterentwickeln. Ausgehend davon erfolgt eine vollständige Verzeichnung der Veränderungen von Textfassung zu Textfassung, so daß der Wortbestand jeder autorisierten Fassung rekonstruiert werden kann. Bei umfangreichen Textentwicklungen werden inhaltlich besonders bedeutsame Varianten durch typographische Mittel hervorgehoben. Dies erleichtert dem Forscher das Studium und gibt den Editoren Empfehlungen, welche Varianten auch in Studienausgaben berücksichtigt werden sollten.

Die Varianten selbst werden in einer Art und Weise wiedergegeben, die möglichst klar den Inhalt und die Abfolge der jeweiligen Textveränderungen zeigt, während die Form, in der sie erfolgte (z. B. als Einfügung über der Zeile, auf dem rechten Rand usw.) in der Regel nicht mitgeteilt wird. Die Variantenverzeichnung geschieht demnach im Prinzip nicht beschreibend, deskriptiv, sondern schlußfolgernd, diskursiv.

Für die Darbietung komplizierter Textumformungen werden in der modernen Editionswissenschaft entwickelte Verfahren angewandt, die die einzelnen Textfassungen bzw. innerhandschriftlichen Schichtungen in chronologischer Folge partiturähnlich untereinanderstellen, angefangen 
von der Zeilen- oder Zeilengruppenparallelisierung einzelner Werkstellen bis zu einer Parallelisierung ganzer Abschnitte oder Werke. Solche Darstellungen erlauben es, sowohl die gesamte Entwicklung einer Werkstelle von Fassung zu Fassung zu überblicken, als auch jede Fassung für sich im Zusammenhang zu lesen. Die Anwendung solcher Verfahren ist auch geboten wegen der großen Anzahl von Handschriften, die in der MEGA zu veröffentlichen sind, und infolge der umfangreichen und schwer überschaubaren innerhandschriftlichen Entwicklungen vor allem in einer Reihe von Marxschen Manuskripten. Sie werden für die Marx-Engels-Edition in der neuen MEGA erstmals angewandt.

Die in der MEGA angewandten Prinzipien für die Darstellung der Textentwicklung entsprechen den spezifischen Schaffensmethoden von Marx und Engels. Darüber hinaus paßt sich die Variantendarbietung - bei Wahrung der Einheitlichkeit innerhalb der Ausgabe im Grundsätzlichen auch den Besonderheiten der verschiedenen Abteilungen der MEGA bzw. der einzelnen Arbeiten an. Bei bestimmten Gruppen von Handschriften wie z. B. bei Exzerpten, die vorwiegend Quellentext enthalten, oder bei Briefen und Artikelentwürfen, die vorwiegend der Mitteilung von Fakten dienen - kann ganz oder teilweise auf die Wiedergabe von Textveränderungen im Verlaufe der Niederschrift verzichtet werden, wenn sie für wissenschaftliche Forschungen ohne Belang sind. In solchen Fällen wird das jeweils gewählte Verfahren in der Textgeschichte mitgeteilt und begründet.

Über alle Details und Besonderheiten der Text- und Variantendarbietung geben die Editorischen Hinweise am Beginn der einzelnen Bände die notwendigen Auskünfte.

IX

Der wissenschaftliche Apparat der MEGA vermittelt alle zur wissenschaftlichen Benutzung der Texte erforderlichen Angaben und Erläuterungen. Er stützt sich dabei auf die Ergebnisse der internationalen Marx-EngelsForschung und bereichert sie zugleich durch die bei der historisch-kritischen Edition gewonnenen Erkenntnisse.

Die Einleitungen, die den einzelnen Bänden oder Gruppen von Bänden vorangestellt werden, umreißen die inhaltliche Aussage und Bedeutung der im Band enthaltenen Arbeiten und zeigen ihre Stellung in der Geschichte des Marxismus.

Der wissenschaftliche Apparat zu jedem Werk beginnt mit einer zusammenfassenden Darstellung der Entstehungs- und Textgeschichte, die eine 
genaue Beschreibung der überlieferten Handschriften und autorisierten Drucke einschließt. Wichtige Aufgaben dieses Teils sind - soweit dies nicht aus dem Text selbst hervorgeht - der Nachweis der Verfasserschaft sowie die Begründung der Datierung, wozu auch für bereits veröffentlichte Arbeiten vielfach eingehende Untersuchungen nötig sind. Hier wird die gesamte autorisierte Textentwicklung analysiert und der chronologische Platz der einzelnen Textzeugen, der Handschriften, Drucke usw. in ihr bestimmt. Ebenso werden in übersichtlicher Form Besonderheiten von autorisierten Übersetzungen eines Werkes im Vergleich mit dem Originaltext mitgeteilt. Weiterhin erfolgt eine Charakterisierung des unmittelbaren Widerhalls der autorisierten Drucke, in der auch wichtige Urteile, Rezensionen und andere Popularisierungsformen erschlossen werden. Die weitere Wirkungsgeschichte wird insoweit beleuchtet, als sie unmittelbar auf die Entwicklung der Texte zurückwirkte. Aus der ausführlichen Beschreibung und inhaltlichen Charakteristik der einzelnen Textzeugen wird die Begründung für die Wahl der Textgrundlage und gegebenenfalls für die Besonderheiten der Textdarbietung und der Variantenverzeichnung abgeleitet.

Die Variantenverzeichnisse haben die autorisierte Textentwicklung darzustellen und bilden einen wichtigen, umfangreichen und charakteristischen Teil des wissenschaftlichen Apparats der MEGA. Die gesonderten Korrekturenverzeichnisse vermitteln alle notwendigen Nachweise über redaktionelle Eingriffe in die im Textteil und in den Varianten wiedergegebenen Autortexte.

Die Erläuterungen bieten alle für das Verständnis des Textes erforderlichen Erklärungen und Hinweise zu historischen Fakten, Parteien und Organisationen, philosophischen, politischen, religiösen u. a. Richtungen und Schulen sowie zu speziellen Begriffen, Vorgängen und Anspielungen. Einen breiten Raum innerhalb der Erläuterungen nehmen die Nachweise der im Text zitierten oder erwähnten Literatur ein, wobei auch aus den Quellen zitiert wird, wenn es zum Verständnis der Textstelle notwendig ist und es sich um Archivalien oder seltene, schwer zugängliche Literatur handelt. Alle Zitate, die Marx und Engels übersetzt haben, werden in den Erläuterungen in der Originalsprache der Quelle wiedergegeben. Von Textpassagen und Zitaten in Griechisch, Latein und anderen alten Sprachen sowie von mundartlichen Wendungen wird eine deutsche Übersetzung angeführt.

Der wissenschaftliche Apparat wird für jeden Text gesondert und in der obengenannten Reihenfolge gebracht. Abschließend erscheint gegebenenfalls ein Verzeichnis nicht überlieferter Handschriften und Drucke solcher Werke oder Briefe von Marx und Engels, deren Entstehung in den 
Zeitabschnitt des jeweiligen Bandes fällt. Dabei werden aus den vorhandenen Zeugnissen Informationen über die verschollenen Texte mitgeteilt.

Die Register zu jedem Band erfassen sowohl den Textteil als auch die Varianten.

Die Literaturregister stellen alle Literatur in alphabetischer Reihenfolge zusammen, die in den Texten direkt oder indirekt zitiert oder erwähnt wird. Sie sind unterteilt in Arbeiten von Marx und Engels, in Arbeiten anderer Autoren und in ein annotiertes Verzeichnis der Periodica.

Die Namenregister verzeichnen die in den Texten direkt oder indirekt genannten Personen in alphabetischer Folge, wobei auch die literarischen und mythologischen Namen mit einbezogen werden. $\mathrm{Zu}$ jedem Namen wird eine knappe Annotation gegeben, die die wichtigsten Angaben zur Person enthält und das Verständnis der jeweiligen Textstelle gewährleistet.

Die Sachregister zu den einzelnen Bänden sind ein wichtiges Hilfsmittel für die inhaltlich-sachliche Erschließung der Texte von Marx und Engels. In ihrer Anlage und Form passen sie sich der Spezifik der zu erschließenden Texte in den einzelnen Abteilungen an.

Wenn es der Inhalt eines Bandes als zweckmäßig erscheinen läßt, werden den genannten Registern weitere spezielle Verzeichnisse (geographische Bezeichnungen, Maße, Gewichte $u$.ä.) hinzugefügt.

Jeder Band der MEGA wird mit Illustrationen ausgestattet: Porträts von Marx und Engels, Faksimiles von Handschriften, Reproduktionen von Titelblättern der Erstausgaben sowie von Zeitungen und Zeitschriften. Im Bedarfsfalle werden auch Karten beigegeben.

Die umfassende Erschließung des literarischen Erbes von Marx und Engels in der historisch-kritischen Gesamtausgabe erfordert eine umfangreiche und vielseitige wissenschaftliche Arbeit. Um die größtmögliche Vollständigkeit der MEGA zu gewährleisten, muß die Suche nach noch nicht aufgefundenen Dokumenten und zeitgenössischen Veröffentlichungen von und über Marx und Engels in aller Welt intensiviert werden. Ein besonderes Anliegen ist es, alle überlieferten Originalhandschriften von Marx und Engels, in wessen Besitz sie auch seien, für die Einsichtnahme zur exakten Textdarbietung in der MEGA zugänglich zu machen. Die wissenschaftliche Kommentierung bedarf einer intensiven Forschungstätigkeit in den verschiedenen wissenschaftlichen Disziplinen. Die Lösung dieser vielfältigen und äußerst komplizierten Aufgaben erfordert die Mitwirkung von wissenschaftlichen Einrichtungen und Gelehrten in vielen Ländern. 
Eine wirksame Unterstützung erhalten die Herausgeber bereits jetzt von zahlreichen Institutionen, Archiven, Bibliotheken und einzelnen Wissenschaftlern. So macht das Internationale Institut für Sozialgeschichte in Amsterdam, in dem ein großer Teil des handschriftlichen Nachlasses von Marx und Engels aufbewahrt wird, seine Bestände den Bearbeitern der MEGA zugänglich.

Das Institut für Marxismus-Leninismus beim ZK der KPdSU und das Institut für Marxismus-Leninismus beim ZK der SED danken allen, die die Vorbereitung der MEGA unterstützten und künftig zu unterstützen bereit sind. Sie sind überzeugt, daß sich die internationalen Verbindungen der an der Marx-Engels-Forschung teilhabenden Wissenschaftler ständig erweitern werden, um so zur erfolgreichen Realisierung des begonnenen Vorhabens beizutragen.

Institut für Marxismus-Leninismus

beim ZK der KPdSU
Institut für Marxismus-Leninismus

beim ZK der SED 